\title{
Criada a Categoria Profissional de Técnico de Administração
}

Merece especial relêvo, embora com atraso de alguns poucos meses, a publicação da Lei $n^{\circ} 4.769$ de 1965, que criou a categoria profissional de Técnico del Administração. Velha aspiração de uma classe, ela representa, sem contestações. como expressão de justiça, a estruturação de uma carreira fundamental no arcabouço do Estado contemporâneo. (NOTA DA REDAC ĀO).

LEI $N^{\circ} 4.769$ - DE 9 DE SETEMBRO DE $1965^{\circ}$

Dispôe sôbre o exercicio da profissão de Técnico de Administração, e dá outras providências.

0 'vesidente dia República,

Faço saber que o Congresso Nacional decreta e eu sanciono a seguinte Lei:

Art. $1^{\circ}$ O Grupo da Confederação Nacional das Profissões
Liberais, constante do Quadro de Ativide

Art. $1^{\circ}$ O Grupo da Confederação Nacional das Profissões
Liberais, constante do Quadro de Ativis à Consolidação das Leis $n^{2} 5.452$, de $1^{\circ}$ de maio de 1943 , fissional de Técnico de Administraçã acrescido da categoria pro-

$\S 1^{\circ}$ Vetado.

$\S 2$ Terão os mesmos direitos e prerrogativas dos bacharéis em Administração, para o provimento dos cargos de de Administração do Serviço Públicos cargos de Técnico diplomados no exterior, em ublico Federal, os que hajam sido após a revalidação dos diplomas regulares de administração, Cultura bem como os que, embos no Ministério da Educação e diplomados em outros curs embora não diplomados, VETADO, ou cinco anos, ou mais, de ativide ensino superior e médio, contem de Técnico de Administração. Vróprias ao campo profissional 
Art. 29 A atividade profissional de Técnico de Administração será exercida, como profissão liberal ou não. VETADo, mediante:

a) pareceres, relatórios, planos, projetos, arbitragens, laudos, assessoria em geral, chefia intermediária, direção superior.

b) pesquisas, estudos, análises, interpretação, planejamento, implantação, coordenação e contrôle dos trabalhos nos campos da administração VETADO, como administração e seleção de pessoal, organização e métodos, orçamentos, administração de material, administração financeira, relações públicas, administração mercadológica, administração de produção, relações industriais, bem como outros campos em que êsses se desdobrem ou aos quais sejam conexos:

c) Vetado.

Art. 3 O exercício da profissão de Técnico de Administração é privativo:

a) dos bacharéis em Administração Pública ou de Emprêsas, diplomados no Brasil em cursos regulares de ensino superior, oficial, oficializado ou reconhecido, cujo currículo seja fixado pelo Conselho Federal de Educação, nos têrmos da Lei n? 4.024, de 20 de dezembro de 1961;

b) dos diplomados no exterior, em cursos regulares de Administração, após a revalidação do diploma no Ministério da Educação e Cultura, bem como dos diplomados, até à fixação do referido currriculo, por cursos de bacharelado em Administração. devidamente reconhecidos;

c) dos que, embora não diplomados nos têrmos das alineas anteriores, ou diplomados em outros cursos superiores a de ensinu médio, contem, VETADO, cinco anos, ou mais, de atividades próprias no campo profissional de Técnico de Administração definido no art. $2^{\circ}$.

Parágrafo único. A aplicação dêste artigo não prejudicará a situação dos que, até a data da publicação desta Lei, ocupem o cargo de Técnico de Administração, VETADO, os quais gozarão de todos os direitos e prerrogativas estabelecidos neste diploma legal.

Art. 49 $\mathrm{Na}$ administração pública, autárquica, VETADO, é obrigatória, a partir da vigência desta Lei, a apresentação de diploma de Bacharel em Administração, para o provimento e exercício de cargos técnicos de administração, ressalvados os direitos dos atuais ocupantes de cargos de Técnico de Administração. 
$\S 1$ : Os cargos técnicos a que se refere êste artigo serão definidos no regulamento da presente Lei, a ser elaborado pela Junta Executivo, nos têrmos do art. 18

§. 2 : A apresentação do diploma não dispensa a prestação de concurso, quando exigido para o provimento do cargo.

Art. 5\% Aos bacharéis em Administração é facultada a inscrição nos concursos, para provimento das cadeiras de Administração, VETADO, existente em qualquer ramo do ensino técnico ou superior, e nas dos cursos de Administração.

Art. 6 São criados o Conselho Federal de Técnicos de Administração (C.F.T.A.) e os Conselhos Regionais de Técnicos de Administração (C.R.T.A.), constituindo em seu conjunto uma autarquia dotada de personalidade juridica de direito público, com autonomia técnica, administrativa e financeira, vinculada ao $\mathrm{M} I$ inistério do Trabalho e Previdência Social

Art. 7: O Conselho Federal de Técnicos da Administração, com sede em Brasilia, Distrito Federal, terá por finalidade:

a) propugnar por uma adequada compreensão dos problemas administrativos e sua racional solução; b) orientar e disciplinar o exercício da profissão de Técnico
de Administração;

c) elaborar seu regimento interno;

d) dirimir dúvidas suscitadas nos Conselhos Regionais;

e) examinar, modificar e aprovar os regimentos interno dos Conselhos Regionais;

f) julgar, em última instância, os recursos de penaliciades impostas pelo C.R.T.A.;

g) votar e alterar o Código de Deontologia Administrativa,

bem como zelar pela sua fiel execução, ouvidos os C.R.T.A.;
h) aprovar anuatia quia;

i). promover estudos e campanhas em prol da racionalização administrativa do Pais.

Art. 8\% Os Conselhos Regionais de Técnicos de Administração (C.R.T.A.), com sede nas Capitais dos Estados e no Distrito Federal, terão por finalidade:

a) dar execução às diretrizes formuladas pelo Conselho $\mathrm{Fe}$ deral de Técnicos de Administração; tração;

b) organizar e inanter o registro de Técnicos de Adninisnesta Lei:

c) jullgar as infrações e impor as penalidades referidas 
d) expedir as carteiras profissionais dos Técnicos de Administração;

e) elaborar o set: regimento interno para exame e aprovação pelo C.F.T.A.

Art. 9: O Conselho Federal de Técnicos de Administração compor-se-á de brasileiros natos ou naturalizados que satisfaçam as exigências desta Lei, e terá a seguinte constituição:

a) nove membros efetivos, eleitos pelos representantes dos sindicatos e das associações profissionais de Técnicos de Administração, que, por sua vez, elegerão dentre si o seu Presidente; tivos.

b) nove suplentes eleitos juntamente com os membros efe-

Parágrafo único. Dois terços, pelo meños dos membros efetivos, assim como dos membros suplentes, serão necessàriamente bacharéis em Administração, salvo nos Estados em que, por motivos relevantes, isso não seja possivel.

Art. 10. A renda do C.F.T.A. é constituída de:

a) vinte por cento $(20 \%)$ da renda bruta dos C.R.T.A., com exceção dos legados, doações ou subvenções;

b) doações e legados;

c) subvenções dos Governos Federal, Estaduais e Municipais, ou de emprêsas e instituições privadas;

d) rendimentos patrimoniais;

e) rendas eventuais.

Art. 11. Os C.R.T.A. serão constituidos de nove membros, eleitos da mesma forma estabelecida para o órgão federal.

Art. 12. A renda dos C.R.T.A. será constituída de:

a) oitenta por cento $(80 \%)$ da anuidade estabelecida pelo C.F.T.A. e revalidada trienalmente:

b) rendimentos patrimoniais;

c) doações e legados;

d) subvenções e auxílios dos Governos Federal, Estaduais e Municipais. ou, ainda, de emprêsas e instituições particulares;

e) provimento das multas aplicadas;

f) rendas eventuais.

Art. 13. Os mandatos dos membros do C.F.T.A. e os dos membros dos C.R.T.A. serão de 3 (três) anos, podendo ser renovados.

§ 10 Anualmente, far-se-á a renovação do têrço dos membros do C.F.T.A. e dos C.R.T.A.

C.F.T. $2^{\circ}$ Para os fins do parágrafo anterior, os membros do C.F.T.A. e dos C.R.T.A., na primeira eleição que se realizar nos 
têrmos da recente Lei, terão, 3 (três), o mandato de 1 (um) ano, 3 (três) o de 2 (dois) anos, e 3 (três), mandato de 3
(três) anos.

Art. 14. Só poderão exercer a profissão de Téenico de Administração os profissionais devidamente registrados nos C.R.T.A., pelos quais será expedida a carteira profissional.

$\S$ 1. A falta do registro torna ilegal, punível, o exercício da profissão de Técnico de Administração.

$\S 2$. A carteira profissional servirá de prova para fins de exercício profissional, de carteira de identidade e terá fé em todo o território nacional.

Art. 15. Serão obrigatòriamente registrados nos C.R.T.A. as emprêsas, entidades e escritórios técnicos que explorem, sob qualquer forma, atividades do Técnico de Administração, enun. ciadas nos têrmos desta Lei.

$\S 1^{\circ}$ Vetado.

$\S 2$ O registro a que se refere êste artigo VETADo será feito gratuitamente pelos C.R.T.A.

Art. 16. Os Conselhos Regionais de Técnicos de Administração aplicarão penalidades aos infratores dos dispositivos desta Lei, as quais poderão ser:

a) multa de $5 \%$ (cinco por cento) a $50 \%$ (cinqüenta por cento) do maior salário-minimo vigente no Pais aos infratores de

b) suspensão de seis meses a um ano ao profissional que demonstrar incapacidade técnica no exercício da profissão, assegurando-lhe ampla defesa;

c) suspensão, de um a cinco anos, ao profissional que, no âmbito de sua atuação, fôr responsável, na parte técnica, por falsidade do documento, ou por dolo, em parecer ou outro documento que assinar.

$\S 1$ V Vetado.

$\S 2$. No caso

dentro do prazo de ce reincidência da mesma infração, praticada da multa em dôbro, será anos, após a primeira, além da aplicação profissional.

Art. 17. Os Sindicatos e Associações Profissionais de Técnicos de Administração cooperarão com o C.F.T.A. para a divulgação das modernas técnicas de administração, no exercício da

Art. 18. Para promoção das medidas preparatórias à execução desta Lei, será constituída por decreto do Presidente da República, dentro de 30 dias, uma Junta Executiva integrada de dois 
representantes indicados pelo D.A.S.P., ocupantes de cargos de 'Técnico de Administraçâo; de dois bacharéis em Administraçäo, indicados pela Fundação Getúlio Vargas; de três bacharéis em Administração, representantes das Universidades que mantenham curso superior de Administração, um dos quais indicado pela Fundação Universidade de Brasilia e os outros dois por indicação do Ministro da Educação.

Parágrafo único. Os representantes de que trata êste artigo serão indicados ao Presidente da República em lista dúplice. caberá:

Art. 19. À Junta Executiva de que trata o artigo anterior

a) elaborar o projeto de regulamento da presente Lei e subrnetê-lo à aprovação do Presidente da República;

b) proceder ao registro, como Técnico "de Administração, dos que o requererem, nos têrmos do art. 3\%;

c) estimular a iniciativa dos Técnicos da Administração na criação de associações profissionais e sindicatos;

d) promover, dentro de 180 (cento e oitenta) dias, à realização das primeiras eleições para a formação do Conselho Federal de Técnicos de Administração (C.F.T.A.) e dos Conselhos Regionais de Técnicos de Administração (C.R.T.A.).

$\S 1$ ? Será direta a eleição de que trata a alinea " $d$ " dêste artigo nela votando todos os que forem registrados, nos têrmos da alinea " $b$ ".

$\S 2^{\circ}$ Ao formar-se o C.F.T.A., será extinta a Junta Executiva, cujo acervo e cujos cadastros serão por êle absorvidos.

Art. 20. O disposto nesta Lei só se aplicará aos serviços municipais, às emprêsas privadas e às autarquias e sociedades de economia mista dos Estados e Municipios, após comprovação, pelos Conselhos Técnicos de Administração, da existência, nos Municipios em que êsses serviços, emprêsas, autarquias ou sociedades de economia mista tenham sede, de técnicos legalmente habilitados, em número suficiente para o atendimento nas funções que lhes são próprias.

Art. 21. Esta Lei entra em vigor na data de sua publicação.

Brasília, 9 de setembro de $1965 ; 144^{\circ}$ da Independência e $77^{\circ}$ da República.

\section{H. Castelo Branco.}

Arnaldo Sussekind.

Publicado no Diário Oficial da União de 13-9-965, págs. 9.337-8. 